\title{
PELIGROSO SUPLEMENTO: DIALÉCTICA Y RETÓRICA EN ARISTÓTELES
}

\author{
Valeria Campos Salvaterra \\ Pontificia Universidad Católica de Valparaíso. Chile
}

Resumen: la disputa entre dialéctica y retórica en los textos de Platón es decisiva para la configuración de una lógica de oposiciones como base normativa de la filosofía griega. Mostraremos cómo Aristóteles, heredero y a la vez crítico, vuelve sobre esta polémica desestabilizando la jerarquía estricta establecida por Platón, mediante una reconfiguración del orden dialéctico a partir de una lógica de la suplementariedad.

Palabras clave: dialéctica, retórica, suplemento, oposición, violencia discursiva

\section{DANGEROUS SUPPLEMENT: DIALECTICS AND RHETORIC IN ARISTOTLE}

\begin{abstract}
The dispute between dialectics and rhetoric in Plato's texts is decisive for the configuration of a logic of oppositions as the normative basis of Greek philosophy. We will show how Aristotle, heir and critic of the former, returns to this controversy by destabilizing the strict hierarchy established by Plato, trough a reconfiguration of the dialectical order by a logic of the supplement.
\end{abstract}

Key words: dialectics, rhetoric, supplement, opposition, violence

Recibido:16.12.2016 - Aceptado: 10.03.2017

Correspondencia: Valeria Campos Salvaterra

Email: valeria.campos@pucv.cl

Dra. en Filosofía. Profesora Asociada Instituto de Filosofía, Pontificia Universidad Católica de Valparaíso. Avda. El Bosque \#1290 Viña del Mar, Valparaíso, Chile. Tel. (56-32) 2274391 / cel. +56-9-92653849. 


\section{BOSQUEJANDO LA HERENCIA: RETÓRICA Y FILOSOFÍA}

a historia de la filosofía occidental ha testimoniado expresa
y enfáticamente su fascinación con la escritura platónica,
especialmente con la constante presencia en ella de un uso "filosófico" de metáforas, analogía, alegorías y otros tropos. Aristóteles fue quizás el primero en captar esa riqueza retórica del texto de Platón, ubicando su escritura entre la poética y la prosa ${ }^{1}$. Siguiendo a Pierre Louis (1945), fueron Cicerón, Quintiliano, Demetrio y Longino algunos de los más famosos comentadores de este estilo propio de los diálogos. Pero no fue hasta el siglo XIX que el lugar de esos tropos retóricos en Platón fue especialmente sistematizado ${ }^{2}$, arrojando resultados que sorprenden por la riqueza del rendimiento que tienen para la filosofía clásica en general. Conocido es el diálogo Fedro, donde Platón establece la posibilidad de una retórica al servicio de la filosofía o la dialéctica. Si bien, el diálogo trata de mostrar cómo no puede haber arte retórico sin soporte en la dialéctica, esto bien puede ser servir para sostener lo inverso: que no puede haber filosofía con fuerza persuasiva sin algún tipo de recurso a la retórica. Platón, en efecto, afirma que si la retórica consta de dicho fundamento en la "verdad", puede ser, además, un instrumento muy efectivo para comunicarla. Con el fin de obtener este estatus, toda retórica necesitaría de la dialéctica para fundarse en cuanto discurso, pues para Platón es siempre la verdad la que comanda los procesos discursivos: es preciso conocer la verdad para poder persuadir mejor mediante el discurso (la persuasión se alimenta de la verdad 260d-e) -dice en Fedro-, ya que sólo así se puede distinguir entre las cosas y aportar mayor claridad (262a). Esto lo dirige a los rétores, diciéndoles que si quieren hablar de lo verosímil, más vale que antes conozcan la verdad, pues de lo contrario no podrán hallar esa semejanza (273d) y tampoco podrán distinguir las cosas según su especie (273e). Como bien lo muestra Louis, las metáforas para Platón, no serían entonces -no podrían ser- meros ornamentos estilísticos, sino, ante todo, instrumentos teórico-pedagógicos que están destinados a expresar las ideas mejor de lo que lo haría un largo desarrollo (Louis, 1945:14). Esta sería,

1 Cf. Diógenes Laercio, III, 19

2 Louis expresa su herencia con autores como Lingenberg, Huber, Bertram, Fisher, Berg (1903), siendo este último el trabajo más consultado. 
según Derrida, una teoría "economista" de la metáfora ${ }^{3}$, que reduciría las figuras retóricas a meros modos de expresión de la idea. Sin embargo, esta economía no sería tan fácilmente sostenible para la complejidad de los diálogos platónicos:

La metáfora estaría a cargo de expresar una idea, de exteriorizar o de representar el contenido de un pensamiento que se llamaría naturalmente "idea", como si cada una de estas palabras o estos conceptos no tuviera toda una historia (a la que Platón no es extraño) y como si toda una metafórica o, más generalmente, una trópica no hubiera dejado en ella ciertas marcas ${ }^{4}$.

Esta sugerencia de Derrida, según la cual el texto platónico no se deja esquematizar completamente reduciendo la función de sus tropos a un mero instrumento al servicio de la idea, es fundamental para cualquier tesis sobre la conexión entre retórica y filosofía. ¿Hay una retórica filosófica? ¿una filosofía retórica? ¿retórica operando en el corazón de la filosofía? Estas son, sin duda, preguntas inquietantes para la filosofía, pero que, sin embargo, nunca han estado ausentes del texto filosófico. Como señalábamos, estaban claramente presentes en Platón, no sólo en el Fedro, sino ciertamente también en centro del diálogo Gorgias, así como también en múltiples lugares periféricos de otros textos (República, Político, Cratilo, etc.). En todos ellos, se hace fuertemente presente no ya una complementariedad entre filosofía y retórica, sino más bien una relación polémica; una tensión entre lo que se pensaba era el discurso propio sobre lo verdadero y aquel solo pendiente de la verosimilitud, peligrosamente cercano al conocimiento engañoso, a la falsa sabiduría. Platón, antes de afirmar la utilidad de la retórica, la denigró estableciendo un orden jerárquico entre su propio arte discursivo y este otro, que para el maestro constituía una mera rutina, una práctica sin regularidad (prágmata, empeiría), mas nunca un verdadero arte (Gorgias, 462c-3). Esta separación jerárquica supone ante todo que, en efecto, exista una límite claramente trazable entre ambas disciplinas discursivas, de modo de poder establecer el dominio de una por sobre la otra. Sin embargo, así como la dialéctica pareciera poder delimitarse con

3 Derrida, J. 1972, p. 263

4 Ibid, p. 266 
claridad frente a la retórica (gran parte del Fedro consiste en ese esfuerzo) , $^{5}$ sobre esta última abundan casi exclusivamente definiciones negativas. El texto platónico escasamente se hace cargo de otorgar características positivas a la retórica, siendo en su mayoría conceptos opuestos a los primariamente establecidos para la dialéctica. En efecto, cómo no tener en mente que la principal referencia directa de Platón a la retórica se da por la vía, también, de un desvío retórico: la famosa comparación de esta con la cocina, mediante el criterio de adulación (Gorgias, 463b1). En ese sentido, podría establecerse no sólo que los límites de la retórica no están del todo claros en Platón, sino que incluso su imposibilidad de clausura tiene que ver justamente con el hecho de que opera fundamentalmente a base de una cierta suplementariedad trópica: una red, un encadenamiento de tropos que no se dejaría nunca dominar, es decir, someter a un orden "con principio y fin", "con cabeza y pies"; un entramado del que no se puede decir cuándo comienza ni cuándo termina, y que se multiplica generando efecto de infinitud mediante la continua suplantación de una palabra por otra, de una imagen por otra, sin linealidad temporal determinable. A esta característica de la retórica Derrida le llama dehiscencia (déhiscence) del suplemento $^{6}$, utilizando también una metáfora - esta vez botánica- que señala la apertura infinita del campo lingüístico, la imposibilidad de su saturación. O como señala Paul de Man, pareciera que la gran y única especificidad de la retórica estriba en que permite suspender radicalmente la lógica y abrir "vertiginosas posibilidades de aberración referencial"

5 Entre otras ideas presentes en el Fedro, resumimos: La persuasión de la dialéctica genera recuerdo (anamnesis), no así la de la retórica (275a); La dialéctica requiere siempre partir por la definición (237c, 265d, 237c-4, 236b); el logos, el discurso dialéctico, es un ser vivo, más precisamente un zôon (264c), mientras que el retórico es siempre letra muerta; el discurso dialéctico divide las ideas naturalmente como las divisiones del cuerpo (266a-c), mientras que en el retórico se observa un des-orden (235a), un sin-pies-ni-cabeza; el dialéctico también es el que tiene conocimiento acabado de la naturaleza de las distintas almas, pues a ellas están dirigidas los discursos (270b), mientras que el retórico se caracteriza por su desconocimiento en esta materia.

6 Derrida, J. 1972, p. 261.

7 De Man, P. 1979, p. 10. 
El siguiente trabajo pretende también abrir camino sobre la base de estas y otras consideraciones, hacia una tesis amplia sobre la imposibilidad de separar radicalmente filosofía y retórica. Suponiendo ya conocido el debate dialéctica-sofística en los textos platónicos, intentaremos llevar a cabo un análisis sobre ambas cuestiones esta vez en el texto de Aristóteles. Mostraremos que en la filosofía del estagirita se observa un progresivo alejamiento de las tesis de su maestro, que lo lleva a establecer un orden más bien horizontal, no ya vertical, entre ambas artes del discurso. Para Aristóteles, la dialéctica no es más, en sí misma, superior a la retórica por razón de su método o de su objeto, sino que sólo alcanzará un cierto lugar privilegiado tomando como criterio aquellos sujetos a quienes está dirigida y los temas con los que trata. Aristóteles eleva a la retórica al nivel de un arte, y quita a la dialéctica su estatuto de ciencia. Esto supone una cierta puesta en cuestión del orden oposicional jerárquico dialéctica/retórica establecida por Platón, derivada de la gran oposición entre lo inteligible y lo sensible 8 , entre el mundo inmutable de las ideas y el mundo devenido de los sentidos, entre lo absolutamente presente y lo meramente ausente. Pues en las raíces mismas del orden metafísico-teológico de Platón se encuentra una oposición radical entre lo presente y lo re-presentado, entre el original y la copia, oposición que servirá de modelo a su vez para toda una cadena de oposiciones que determinan el pensamiento occidental hasta hoy. Quizás el más importante par de opuestos para hablar de la retórica sea habla/escritura, el que es tratado por Platón también en Fedro, a partir del mito egipcio (274c y sgtes.). Para Derrida, este par de opuestos se ha mantenido vigente por mucho tiempo después de Platón, a pesar del rechazo histórico que ha tenido inteligible/sensible 9 . De ahí que habla/ escritura tomen el puesto de paradigma de opuestos metafísicos para buena parte de la tradición filosofía, muy bien articulado posteriormente a partir del concepto de signo, pues es gracias al signo que el ordenamiento lógico-racional del mundo puede acontecer. Compuesto a su vez a partir del binomio significado-significante, el signo guarda dentro de sí la diferencia fundamental que da vida a la época del logos: "La diferencia entre significado y significante pertenece de manera profunda e implícita

8 Derrida, J. 1967 b, p. 24.

9 Derrida constata la jerarquía entre habla y escritura en los textos de Rosseau, Levi Strauss y Saussure, entre otros. Cf. Derrida 1967b. 
a la totalidad de la extensa época que abarca la historia de la metafísica"10.

Lo anterior implicaría una importante dificultad para la filosofía en general de desligarse de aquella determinación denigrante de la retórica. Una línea de herencia, entonces, llevaría siempre hasta Platón en este sentido. Y si Platón es el padre, Aristóteles tendría que ser el hijo: continuador de algunas de sus tesis, a la vez que gran renovador de muchas otras. Aristóteles nota que la dialéctica platónica no siempre es capaz de llegar a la verdad plena y, por ello, se identifica con la filosofía, mas no con la sabiduría absoluta. La dialéctica es, para Platón, la ascesis de un pensamiento en movimiento que tiene como término la verdad del ser o de la idea, pero que no se alcanza perfectamente mientras se es dialéctico, es decir, mientras se hace filosofía. La dialéctica es el camino más certero para la verdad, pero muchas veces parece fallar. Los diálogos aporéticos dan prueba de aquello, y la necesidad de Platón de recurrir a los mitos típicos recursos retóricos-, a la escritura en términos metafóricos-como cuando se dice "escritura del alma" 11 - y literales -en Las leyes ${ }^{12}$ - e incluso a la opinión verdadera (doxa alethés) como base para el conocimiento, son también pruebas de la incapacidad dialéctica. Pero si la dialéctica no tiene plena capacidad de dar con la verdad, ¿Por qué Platón la caracteriza como la ciencia suprema, como la "coronación de todas las ciencias" (Rep. 534e ) ?

Intentaremos establecer que, debido a esta incapacidad del discurso dialéctico de llegar a la verdad plena sin necesidad de persuasión y de utilización de elementos retóricos, Aristóteles baja del pedestal epistémico a la dialéctica, la sitúa en el mismo ámbito que la retórica, aunque manteniendo una cierta jerarquía; pero, a diferencia ya de Platón, una que sólo es posible a partir de criterios extrínsecos a ambas disciplinas tomadas en sí mismas. Sostendremos que Aristóteles le da a la retórica el carácter de suplemento de la dialéctica, en la medida en que tiene su misma función: la de dar razones acerca de lo probable. Siguiendo a Derrida, esta exposición mostrará cómo aquella lógica oposicional puede transformarse

10 Derrida, J. 1967b, p. 23.

11 En Fedro, el logos hablado se tematiza, después del mito egipcio, como escritura del alma, es el discurso que "se escribe con ciencia en el alma del que aprende" (Phdr. 276a-5).

12 Derrida, J. 2001, p. 169. Se dice, sobre Leyes, que Platón tiene la "necesidad de inscribir a la dialéctica en el tipos". 
en una cierta lógica del suplemento, que manifiesta la imposibilidad de clausura de la filosofía y su imposibilidad de separarse de la retórica. A la luz de esto, se concluirá que la retórica no era una práctica aislada en la antigua Grecia, reservada a los oradores demagogos y poco instruidos, sino que una práctica ubicua, que se expande más allá del ámbito de la sofística -si acaso existe también un "ámbito" clausurado asociada a ella. La ubicuidad de la retórica es la ubicuidad de la persuasión como fin de todo acto discursivo, pues incluso los filósofos, como Sócrates y Platón, hombres de elevado espíritu y con envidiable conexión con la verdad, fueron grandes oradores, los más grandes oradores, los más instruidos en las técnicas de persuasión. Si acaso son más filósofos que oradores o más oradores que filósofos, es algo que no se puede distinguir con plena certeza; la indecidibilidad entre ambas categorías se manifiesta a penas se ponen en juego.

\section{La nueva dialéctica}

Al buscar en su Retórica y en Tópicos -libro dedicado a la dialécticala misma jerarquía que realizó Platón respecto de ambas disciplinas discursivas, nos encontramos con una sorpresa: la dialéctica no tiene ni las mismas funciones, ni exactamente los mismos fines, ni el mismo estatus que tiene en los diálogos platónicos. Es como si, manteniendo un cierto desprecio por la escritura -desprecio que no sorprende por su presencia constante en toda la época del logos-Aristóteles se haya desilusionado, haya desestimado - por razones más profundas que las que se dejan leer-a la dialéctica que profesaba su maestro. En Tópicos se lee: "el silogismo dialéctico es el que saca sus conclusiones de proposiciones simplemente probables" (cap 1, §3). Asistimos aquí a una ampliación del ámbito de la dialéctica y, por lo tanto, del ámbito de lo racional, pues éste no se ocupa simplemente de las verdades científicas necesarias. En este sentido, Tomás Calvo Martínez ${ }^{13}$ afirma:

No siempre, sin embargo, nos es posible argumentar científicamente. Muy a menudo nos vemos en la necesidad de razonar en ámbitos no susceptibles de demostración. Piénsese, por ejemplo, en el ámbito de la deliberación sobre asuntos morales o políticos, en general, en aquellos dominios en que se enfrentan entre sí

13 Calvo, T. 1996, p. 19 
opiniones discordantes. También en estos casos cabe ser razonable, es posible comportarse racionalmente. Y un modo de comportarse racionalmente en estos casos es precisamente argumentar.

Esto implica que muchos de los razonamientos dialécticos, al partir de proposiciones meramente probables, se estructuran sobre la base de opiniones comunes y reputadas (éndoxa). Como se dice en Tópicos 105b30: "En vistas a la filosofía, debemos tratar las cuestiones conforme a la verdad, pero para la dialéctica sólo conforme a la opinión". Para Platón, esta afirmación sería inadmisible, primero, porque dialéctica y filosofía se identifican; segundo, porque la dialéctica es la ciencia suprema (Rep. 534 e), aquella que no puede nunca basar sus argumentos en la mera opinión, sino en la verdad (Rep. 534b). El estatuto epistémico de la dialéctica platónica impide que sean objeto de ella cuestiones que pueden ser de diversos modos. Sólo lo que él llama "opinión verdadera" (doxa alethés) se exceptúa de esa consideración, pues ella parece ser un punto de partida para el conocimiento, siempre y cuando se la "ate" bien mediante el razonamiento para que no se diluya (Menon, 85b20, 97d-e). La opinión verdadera tiene algo de ambas dimensiones, pues es frágil e intuitiva, pero cierta -no sólo probable o mayoritariamente aceptada- y está capacitada para convertirse en saber ${ }^{14}$.

14 La doxa alethés tratada en Menon puede ser un objeto de análisis bastante confuso. Por un lado, es igualmente útil que la ciencia para guiar a los hombres (96c-97d), pero para que pueda ser una guía confiable, debe convertirse en saber mediante el razonamiento. Sin embargo, el diálogo está dedicado a la cuestión de si la virtud puede o no ser enseñada. Platón llega a la conclusión de que no puede haber maestros de virtud, por lo que se deduce que la virtud no es una ciencia. Entonces, se concluye que la virtud está más cerca de la opinión verdadera (99b), o es la capacidad de actuar según opiniones verdaderas. Sin embargo, uno podría preguntarse: ¿la virtud es una opinión verdadera que nunca se ata y que, por lo tanto, viene y va sin mantenerse fija en el sujeto virtuoso? Si se atara, se convertiría en ciencia y sí podría ser enseñada. Pero si no se ata, no formaría parte del carácter de los hombres. La confusión se agranda cuando se dice que la opinión verdadera es el producto de la reminiscencia (86a). Sin embargo, lo que interesa rescatar aquí es la posibilidad que tiene la opinión verdadera de ser origen y fundamento para las ciencias. Para las grandes mayorías, la opinión verdadera podría establecerse como su único saber posible; para los dialécticos, por el contrario, sería sólo el punto de partida para una episteme segura y firme. 
Por su parte, Aristóteles distingue en los primeros pasajes de Tópicos el modo de razonamiento dialéctico del modo propiamente científico, aquel que, mediante un silogismo con premisas verdaderas y primitivas -es decir, que son evidentes y convencen por sí mismas-, lleva a una demostración apodíctica (100a25-28); la deducción dialéctica, por otro lado, razona a partir de opiniones reputadas (éndoxa) (100a29), es decir, las que son aceptadas por todos, o por la mayoría, o por los sabios (100b20). El razonamiento científico-demostrativo, por Platón asignado a la dialéctica -en la medida en que ella permite contemplar la Idea- es desplazado por Aristóteles fuera de ella, al ámbito de las ciencias -entre ellas la filosofía-, pues son las ciencias las que verdaderamente demuestran, no sólo especulan; las que contemplan la verdad. El carácter aporético de gran parte de los razonamientos dialécticos de Platón alejan a la dialéctica de lo que puede llamarse demostración concluyente, ya sea por deducción o por inducción. El logos epistémikós es, para Aristóteles, el terreno de la verdad, no así el logos dialéctikós, que se encarga solamente de dar razones, por lo que su aplicación es práctico-productiva y no se ocupa de objetos de pura contemplación ${ }^{15}$. Es, en ese sentido, un logos vacío, un discurso meramente formal, que puede ser llenado con toda clase de temáticas distintas.

En Retórica es donde se lleva a cabo esta definición de la dialéctica como disciplina que trata "de aquellas cuestiones que permiten tener conocimientos en cierto modo comunes a todos y que no pertenecen a ninguna ciencia determinada" (1354a1-4). Este pasaje en el que Aristóteles define la función de la dialéctica es el mismo en el que define la función de la retórica: ambas operan de la misma manera, "puesto que ni una ni otra constituyen ciencias acerca de cómo es algo determinado, sino simples facultades de proporcionar razones" (1356a33). Ambas son facultades vacías que dan razones que abarcan todo el campo de la praxis humana, siendo su aplicación universal y no constreñida por ningún género. Al ser un arte de razonar y argumentar, ambas se presentan como artes que pueden concluir, respecto de una misma materia, cosas contrarias (1355a34). Esta función es adjudicada únicamente a la retórica en los escritos de Platón, y despreciada por llevar a equívocos y no pretender alcanzar una verdad unívoca-cosa que hacían expresamente los llamados "sofistas" ${ }^{\text {. }}$. Y aunque

15 Racionero, Q. 1990, p. 162.

16 Cf. Discursos Dobles, en "Sofistas: Testimonios y fragmentos", Gredos, 1996. 
pareciera que hay en Aristóteles una dimensión epistémica de la dialéctica, esta parece no ser ni la única ni la primordial, pues su propósito es trabajar en al menos tres aspectos: el entrenamiento intelectual, la conversación y, finalmente, la ciencia filosófica (Top. 101a25-27). Respecto los dos primeros, no se dice mucho en el tratado, pero no por eso es menor su importancia, pues el ejercicio ayuda a formar habilidades argumentativas, y la conversación permite conocer los diversos éndoxa que le darán cuerpo a toda argumentación ${ }^{17}$; ambas dimensiones del uso de la dialéctica serán directamente funcionales a la retórica, pues el conocimiento tanto del arte argumentativo como de los éndoxa son necesarios para la persuasión. Es respecto de la ciencia filosófica de lo que más trata Aristóteles en este apartado, afirmando que la dialéctica es funcional porque:

La habilidad de argumentar en ambos lados de un tema nos hará detectar con mayor facilidad la verdad y el error sobre los diversos puntos de vista que se alcen. Tiene también un uso en relación a los principios usados en las distintas ciencias. Pues es imposible discutirlos solamente a partir de los principios propios de la ciencia particular que tengamos, teniendo en cuenta que los principios son primitivos en relación con todo lo demás: es a través de opiniones reputadas sobre ellos que esto debe ser discutido, y esta es una tarea propia y más apropiada de la dialéctica; por lo que la dialéctica es un proceso crítico en el que está el camino a los principios de todas las ciencias (Top. 101a35-101b4).

La dialéctica permite dar con los primeros principios de las ciencias, según este pasaje, pero siempre teniendo en cuenta los éndoxa que existan sobre ellos, haciendo de la dialéctica un razonamiento crítico. Si bien esta función crítica es similar a la de la dialéctica platónica, se diferencia en que, más que refutar las opiniones comunes sobre las ciencias y hacerlas a un lado para dejar que brille el saber, la dialéctica aristotélica se vale de ellas como condiciones necesarias para llegar a los principios. Quizás, la razón más apropiada para la necesidad de éndoxa en el razonamiento dialéctico utilizado por las ciencias, sea el carácter empírico que el estagirita les atribuye en su base. A diferencia de Platón, ciertos conceptos

Introducción, traducción y notas de Antonio Melero Bellido

17 Covarrubias, A. 1998, p. 48 
se dan por inducción a partir de una multiplicidad de casos concretos, y es en ese proceso de ir de lo particular a lo universal (105a14) donde los éndoxa cumplen su función científica. La argumentación en la dialéctica de Aristóteles no sólo se da por silogismos, sino también por inducción, y en ésta los éndoxa, en cuanto opiniones respetadas, son puestas como sustrato para evaluar qué tienen de verdaderas y qué de falsas en pos de una buena inducción ("La habilidad de argumentar en ambos lados de un tema nos hará detectar con mayor facilidad la verdad y el error sobre los diversos puntos de vista que se alcen"). Pese a lo dicho, este "camino hacia los principios" que promete la dialéctica señalado en Tópicos entra en tensión con lo que se dice en Analiticos Posteriores 100b5-17, a saber, que los principios de las ciencias no son conocidos mediante ciencia, sino intuitivamente. Sin querer ver aquí una contradicción, Tomás Calvo señala que lo que se dice en Analíticos Posteriores se refiere a los principios ya establecidos, mientras que lo que se dice en Tópicos es en vistas de su establecimiento ${ }^{18}$. Mientras que el conocimiento inmediato de los principios prescinde de todo elemento dóxico, la inducción señalada en Tópicos, si es útil en relación con el establecimiento de los principios, no puede dejar los éndoxa - $\mathrm{u}$ opiniones reputadas- fuera de su campo de aplicación sin perder buena parte de su eficacia. La dialéctica platónica, por otro lado, no puede basarse en opiniones respetadas o mayormente sostenidas, sino sólo -y no siempre- en la misteriosa "opinión verdadera"; en la medida en que la dialéctica es una episteme, y la más alta de todas, sólo trata con proposiciones verdaderas que permiten únicamente una ciencia deductiva, refutando inmediatamente las que son sólo opiniones contingentes sobre un tema particular.

Sin embargo, la dialéctica aristotélica, por útil que sea a la ciencia, no es más que una techné: enmarcada en el ámbito de la producción de razones, no puede circunscribirse sólo a la ciencia ni a la demostración, aunque muchas veces le sea de gran ayuda. Y puesto que sólo puede haber ciencia cuando los razonamientos se refieren a un género, la dialéctica no produce conocimiento científico ${ }^{19}$. Pero la ayuda que le presta a las ciencias no es simplemente periférica, sino que está en el corazón mismo de la ciencia inductiva, pues abre el horizonte de la discusión científica, expande sus límites más allá de lo axiomáticamente verdadero. Trabajar

18 Calvo, T. 1996, p. 20.

19 Ibídem. 
con la probabilidad permite abrirse a la pluralidad y así generar juicios con mayor pretensión de universalidad, aun cuando la dialéctica aristotélica se aleje de la ciencia de las cosas y su silogismo concluya a partir de consideraciones demasiado generales ${ }^{20}$. Como dice Pierre Aubenque, la probabilidad dialéctica "siendo correlato de los discursos universales, en el doble sentido de discurso sobre la totalidad y discurso admitido por la universalidad de los hombres, es inferior, sin duda, a la demostración; pero interviene siempre que la demostración es imposible (...): corrige entonces nuestro alejamiento de las cosas mediante el recurso al consentimiento y a la autoridad de los hombres"21. La dialéctica aristotélica ocupa el lugar que la dialéctica platónica deja en abandono, arrojado al devenir de la aporía; es así un complemento para las ciencias, que permite extenderlas más allá de los límites de la demostración y ampliar el círculo de los científicos, especialmente mediante la inducción: "En la discusión hay que emplear la deducción para razonar con los dialécticos más que con el vulgo; la inducción, en cambio, es la más útil para el vulgo" (Tópicos, 157a15-20), pues esta última es más clara y convincente, es más apropiada para la percepción sensible que para el razonamiento y es, por eso, aplicable en general a las masas (Tóp. 105a16-18). He aquí otra función de la inducción dialéctica: lograr que las masas comprendan un determinado asunto, pues, como dice Aubenque, en este caso la demostración no generará necesariamente asentimiento. Esta es distinta de la inducción que descubre principios, pero igualmente pertenece a las formas de argumentación dialéctica. Sin embargo, desde el momento en que Aristóteles ocupa el nombre que su maestro dio a la ciencia más excelsa para referirse a este arte vacía -aunque útil y de amplio alcance- la convierte en un suplemento de aquella, en un arte -menos perfecta que la ciencia- que reemplaza con manifiesta eficacia a aquella dialéctica con grandes pretensiones, pero muchas veces limitada; se torna así tan o incluso más valiosa que la "ciencia suprema".

\section{Dialéctica y retórica}

El rebajamiento de la dialéctica que hace Aristóteles, y su carácter suplementario respecto de la dialéctica platónica, la acercan cada vez más a la retórica, aquella arte denostada por Platón, expulsada fuera de los terrenos

20 Aubenque, P. 1974, p. 282, nota 132.

21 Ibid., p. 251. 
de la república ideal ${ }^{22}$. Y aunque la dialéctica de Aristóteles tenga mucho más en común con la retórica que con la dialéctica platónica, el estagirita se cuida de no identificar totalmente ambas artes discursivas; pero sí lo hace parcialmente, cuando dice que la retórica es antístrophos de la dialéctica. La palabra antístrophos ha traído bastantes problemas a los traductores, y pareciera que en castellano no podemos encontrar una palabra que exprese literalmente su significado. Por ello, muchos han optado por dejar la palabra griega original, con alguna explicación. En la edición de Gredos, traducida por Quintín Racionero, se afirma la dificultad del término, señalando su carácter metafórico: se dice que es un vocablo creado por Platón a partir de antistréphein, que "designa el movimiento de réplica, idéntico pero inverso al de la estrofa, con el que el coro se desplazaba en las representaciones teatrales. El sentido de la metáfora es, pues, que entre dialéctica y retórica se da, a la vez, identidad y oposición"23. Racionero afirma así que "Este doble significado [de identidad y oposición] no queda recogido, hasta donde yo conozco, por ninguna de las traducciones que se han propuesto del término _-"análoga", "correspondiente", "correlativa"_, todas las cuales connotan excesivamente la identidad" 24 . Por un lado son idénticas: ambas son facultades de dar razones, independientes de toda metafísica y de todo conocimiento particular. Además, ambas se alejan del terreno de la ciencia y se basan en el uso de éndoxa para argumentar. Por otro lado, son contrarias: la retórica no se puede reducir a la dialéctica, sino que se nutre de su esquema argumental, pero se diferencia radicalmente según su campo de aplicación, los modos específicos de argumentación y el tipo de destinatario o receptor al que se dirigen ${ }^{25}$. Platón, en el Gorgias, utiliza el vocablo en cuestión fuera del contexto teatral antes señalado para analogar a la retórica con la cocina, en la medida en que ambas no hacen más que

22 Platón acepta, sin embargo, a la retórica, pero despojada de todos sus recursos a la Doxa y a la adulación. Sólo entonces puede considerarse como techné y así identificarse con la dialéctica o, al menos, subsumirse a ella. En este diálogo, Platón da las pautas para un verdadero arte retórico que, por supuesto, está estructurado en base al logos dialéctikós (Fedro: 237c, 265d, 236b, 262a, 273de).

23 Racionero, Q. 1990, p. 161. Nota 1. Cursivas nuestras.

24 Ibíd., p. 161. Nota 1.

25 Covarrubias, A. 1998 , p. 85. 
procurar placer y no un bien verdadero a la salud del alma y el cuerpo (462b7 y ss.). En ese sentido, ambas se dedican a adular a los hombres, con fines distintos a los que se deberían perseguir. Esto podría hablarnos de una cierta herencia platónica en el uso de este vocablo por parte de Aristóteles, sin embargo, pareciese que el uso de antistrophos tiene una connotación muy distinta en la Retórica aristotélica. Según la interpretación de A. Vallejo Campos: "La primera línea del tratado aristotélico [Retórica] es una reivindicación de la retórica en contra del punto de vista tradicionalmente sostenido por el platonismo... Elegir esta expresión [antístrophos] y poner la dialéctica al lado de la retórica no era para mostrar la fidelidad al espíritu del maestro, sino para expresar la distancia insalvable que le separaba de él en este punto" ${ }^{26}$. Más que denostar a la retórica con el uso de la palabra antistrophos, pareciera que Aristóteles quiere elevarla: por sobre las críticas de Platón, al nivel de la dialéctica, para lo cual necesita también bajar a ésta última de su pedestal platónico. Y prueba de esto se halla, entre otros, en el pasaje de Retórica 1359b13-16: "Pero cuanto más se trate de equiparar a la dialéctica o a la propia [retórica], no con facultades, sino con ciencias, tanto más se estará desfigurando inconscientemente su naturaleza. Al pasar con ello a constituir ciencias concernientes a determinadas materias establecidas y no sólo a discursos".

La retórica, además de ser antístrofa de la dialéctica, es también una parte (mórión ti) de ella (1356a31 y ss.; 1359 b12 y ss., entre otros). La retórica busca dar las pruebas que pueden producir persuasión en los oyentes: "entendamos por retórica la facultad de teorizar lo que es adecuado en cada caso para convencer" (1356a25), y esta es una especie de demostración, pero sin la fuerza necesaria de la demostración científica. La posibilidad de persuasión en retórica se da gracias al entimema, o silogismo retórico, que busca articular de mejor manera los elementos necesarios para persuadir. Sin embargo, para hacer un buen entimema es necesario primero saber hacer un buen silogismo, lo que, según Aristóteles, corresponde al dialéctico (1355a12). Es decir, todo retórico debe manejar en menor o mayor medida los recursos del dialéctico, por lo que todo dialéctico puede llegar ser un retórico sin mayores dificultades. La retórica es, por tanto, paraphyés de la dialéctica (1356a26), es decir, una especie de ramificación. La metáfora apuntaría a la dependencia que la retórica tiene con la dialéctica en cuanto a su estructura argumentativa. Sin embargo, esta

26 Vallejo Campos, A. 1994, p. 78. 
traducción no logra explicitar el carácter autónomo que logra la retórica en ciertos aspectos de la argumentación, pues sus discursos se ordenan a partir de criterios distintos que los de la dialéctica, p.e. los oyentes a los que está dirigida -masas indocumentadas-y el ámbito en el que se desarrolla -asuntos prácticos públicos. Seguiremos aquí la traducción de Racionero, según la cual el paraphyés sería algo análogo a lo que en botánica es un esqueje: un vástago que es a la vez independiente pero de igual naturaleza que la planta de la que proviene ${ }^{27}$. Hay una relación de condicionantecondicionado entre dialéctica y retórica, que hace que se mantenga hasta cierto punto la jerarquía platónica; pero, a la vez, la retórica se alza como reina de su propio ámbito discursivo: el de los asuntos públicos que se tratan frente a grandes audiencias poco instruidas. Sin el árbol de la dialéctica, el esqueje del que nace la retórica como arte independiente no sería posible. Pero una vez sacado el esqueje, este puede crecer por sí mismo e incluso más fuerte que su padre árbol. Algo así, al parecer, le sucedió también a Aristóteles respecto de Platón.

Recapitulando, mientras la dialéctica es el arte de articular silogismos -en general- para llegar a un cierto juicio sobre lo probable, la retórica es el arte de articular silogismos adecuados para persuadir, pero sobre algo también meramente probable. Hay una sutil diferencia entre ambas, pues la dialéctica no busca armar silogismos para dar con lo más persuasivo, sin embargo, en la medida en que busca una decisión sobre lo meramente probable -y no una demostración de lo verdadero- finalmente utiliza elementos que pretenden convencer a cerca de algo. La persuasión es, por tanto, un fin que comparten ambas artes, y no es algo propio sólo de la retórica como proponía Platón. Si la dialéctica no trabaja a partir de lo verdadero, sino sólo de lo probable, el asentimiento a sus conclusiones no puede darse necesariamente ni en todos los casos, puesto que no se deriva necesariamente del valor veritativo de las premisas, ni del grado absoluto de necesidad, ambos propios de la apódeixis ${ }^{28}$. El asentimiento, entonces, se da por persuasión, puesto que la dialéctica no tiene su referente en la cosa, como las ciencias, sino en la selección de los mejores medios argumentativos. El silogismo dialéctico está hecho también para persuadir de ciertas tesis, y se diferencia del entimema en que este último está hecho para persuadir a las mayorías, a aquellos que se convencen más fácilmente

27 Racionero, Q. 1990, pp. 178-179, nota 38.

28 Covarrubias, A. 1998 , p. 62 
por la percepción sensible que por vía racional. De ahí la utilidad práctica de la inducción, como se vio.

Las diferencias entre ambas artes parecen acortarse aún más cuando se tiene esto en cuenta, pues ambas se sustentan en lo probable, y esa es -si se nos permite- su causa material. Lo probable (eikós) es descrito por Aristóteles en el mismo texto como "lo que sucede la mayoría de las veces, pero no absolutamente, como algunos afirman; sino lo que, tratando de cosas que pueden ser de otra manera, guarda con aquello respecto de lo cual es probable la misma relación que lo universal respecto de lo particular" (1357a35). Lo probable es lo que sucede la mayoría de las veces, pero sólo en cuanto coincide con una opinión generalmente admitida o plausible (éndoxos). La opinión compartida, lo plausible, es aquello que le da una cierta validez epistemológica a los juicios de probabilidad, sin embargo, no le otorgan valor de verdad pleno, sino sólo de verosimilitud. Por ello, es requerimiento de ambas artes que versan sobre lo probable el buscar argumentos que permitan decidir sobre lo verosímil: la retórica busca hacer que eso verosímil se acerque más a lo verdadero o falso, dependiendo de qué es lo conveniente; la dialéctica, al parecer, busca lo mismo -hacer que lo verosímil adquiera apariencia de verdadero o falsotambién según cierta conveniencia, pero no aquella que promueve los asuntos prácticos de la polis, sino, como se dijo, la conveniencia respecto del entrenamiento, el diálogo y la asistencia a las ciencias. Por lo anterior, es propio del retórico reconocer lo conveniente de lo que simplemente parece conveniente, así como también es propio del dialéctico reconocer la diferencia entre silogismo y silogismo aparente. Esta capacidad de reconocer entre lo real y lo aparente, propia de ambas artes, es necesaria en la medida en que la verdad es siempre mejor y más apta para los silogismos y las pruebas por persuasión (1355a39). Y aunque le corresponde a una misma facultad reconocer lo verdadero y lo verosímil, los hombres tienden de un modo suficiente a la verdad, es decir, tienen la capacidad para llegar a ella la mayoría de las veces. Esto implica que sólo está en condición de discernir sobre lo verosímil quien está en la misma disposición con respecto a la verdad (1355a15-20). Otra sumisión: si quiero decidir sobre lo verosímil, debo ser ya capaz de dar con la verdad. Sin embargo, respecto de la retórica se dice que los hombres "se persuaden por el discurso cuando les mostramos la verdad, o lo que parece serlo, a partir de lo que es conveniente en cada caso" (1356a20). Es decir, para persuadir mediante el discurso retórico no es estrictamente necesaria la verdad, pero sí suficiente. 
Pero si no poseo una determinada verdad, puedo usar un juicio verosímil y esperar iguales o similares resultados. En conclusión, si bien para hacer un juicio de verosimilitud debo ser ya capaz de hacer uno de verdad, para persuadir no se requieren necesariamente argumentos verdaderos, sino tan sólo verosímiles o plausibles. De la misma manera, la dialéctica como arte de la argumentación no requiere necesariamente, para llegar a su fin, de argumentos siempre verdaderos, sino también de argumentos verosímiles.

La dialéctica y la retórica se diferencian principalmente por elementos externos a ellas mismas en cuanto artes discursivas: 1) por el ámbito temático sobre el cual versan los discursos y 2) por los interlocutores. En todo lo que respecta a la estructura misma de la argumentación, las bases son las mismas - o se requiere de una, la dialéctica, para poder construir la otra, la retórica. Más aún, todas las diferencias de estructura argumentativa se dan en vistas a ambos elementos nombrados (tema y público), pues el entimema sólo es necesario en la medida en que existen asuntos públicos que hay que discutir con todo el mundo, no con unos pocos instruidos. Sin esa parte de la población, la retórica no tendría sentido. Y este criterio, el del oyente, parece ser por ello más fuerte que el del ámbito temático, pues en una hipotética ciudad de sabios, incluso los asuntos públicos se discutirían dialécticamente. ¿Es esto sostenible? ¿O es posible que la retórica también tenga una utilidad entre dialécticos instruidos? ¿Es necesario, a veces, utilizar recursos retóricos en conversaciones dialécticas y, si es así, de qué depende? Si en la ciudad de sabios hay que decidir sobre lo más conveniente políticamente en una circunstancia determinada, es posible que la retórica haga su aparición en escena, pues las cosas públicas son tan contingentes -es decir, no se rigen por leyes necesarias- que su decisión, más que un fundamento, requiere de una apuesta. Y si la apuesta se caracteriza por el abismo de fundamento, por la falta de un piso certero desde el cual afirmar algo, entonces todo vale para sustentarla, incluso los recursos retóricos.

\section{EI suplemento}

Esto nos lleva a una posible tesis: en todos los casos en que la dialéctica falle, es posible utilizar la retórica, pues ésta puede reemplazarla muy eficazmente, casi sin que se noten diferencias. Esto es patente cuando Aristóteles dice que la dialéctica sólo está dirigida a las personas sabias o de gran capacidad intelectual. Si intento ocupar la dialéctica para probar algo ante las mayorías indocumentadas el fracaso será rotundo. En este 
caso, entonces, puedo suplir la dialéctica con la retórica, justamente porque es un esqueje de aquella, es decir, son de la misma naturaleza. La retórica, entonces, se justifica sólo en cuanto hay que hacer discursos públicos que sean capaces de convencer a las masas poco instruidas, de lo contrario no la necesitaríamos, pues ya tenemos a la dialéctica. Sin embargo, la retórica es un peligroso suplemento: se podría sostener que muchas veces, al reemplazar a la dialéctica, la retórica aporta más valor al discurso, pues puede hacerlo más efectivo y extensivo, más persuasivo a la postre. Esto es patente en la medida en que Aristóteles incluye, a partir del libro segundo de la Retórica, a las pasiones como modos de argumentación retórica legítimos ${ }^{29}$, además del carácter del orador, primordial para generar credibilidad. El entimema, el ejemplo y el signo son los principales recursos retóricos, y los tres son derivados de la dialéctica como arte del silogismo y de la argumentación. Pero cuando los silogismos no son suficientes, cuando la dialéctica tiende a fallar, aparecen otros recursos, exclusivos del arte retórico, que cumplen la función de suplir las carencias de la dialéctica, su alcance limitado en términos de persuasión. En el libro II de Retórica se habla ya al comienzo de la importancia de la credibilidad de los oradores, pues si su carácter es sensato, virtuoso y benevolente, serán más persuasivos (1378a5-10). Así mismo, las pasiones tienen un importante papel que cumplir, pues son "las causantes de que los hombres se hagan volubles y cambien en lo relativo a sus juicios, en cuanto que de ellas se sigue pesar y placer" (1378a19-22). Estos elementos externos a la argumentación silogística son, sin embargo, absolutamente útiles cuando se trata de hacer que las grandes masas realicen un juicio de verdad sobre algo meramente probable. Y hasta podría pensarse que no sería imposible que un gran intelectual se deje convencer en algunas ocasiones tanto por la personalidad de su interlocutor, como por las emociones que él le hace sentir. Esto se refuerza si notamos que el mismo Aristóteles constata una cierta ampliación temática -al parecer progresiva- de la retórica, es decir, considera la posibilidad de que ella se utilice cada vez más para hablar de temas más diversos: “...actualmente se han introducido en [la retórica] muchas más materias de las que corresponden a sus reflexiones propias" (Ret. 1359b67-9 -cursivas nuestras). Actualmente (nún), dice

29 Cf. Fortenbaugh, W. 1970. En la página 134: "I shall argue rather generally that the Rethoric's análisis of individual emotions did receive the close attention of Aristotle and so should not be passed off as popular and imprecise". 
Aristóteles, como si estuviese en presencia de un cambio histórico que amplía el ámbito temático de la retórica más allá de los límites con que, por ejemplo, la concibió Platón. Aunque eso no implica, para el estagirita, que pueda considerarse como ciencia, lo mismo que la dialéctica. Si el único límite fuerte y necesario para la retórica -y para la dialéctica- es el campo temático de las ciencia, entonces ¿qué impide que se traten temas dialécticos de modo retórico?

La dialéctica, si bien tiene una cierta superioridad sobre la retóricaal modo del esquema condicionante-condicionado-puede ser reemplazada por ésta logrando el mismo fin, e incluso de manera más efectiva. La retórica se comporta, entonces, como suplemento de la dialéctica, como aquello que puede reemplazarla -incluso en su campo temático, como vimos-, pero a partir de algo exterior a la dialéctica misma, es decir, gracias a los argumentos puramente retóricos como son el carisma y la capacidad de apasionar. El suplemento siempre reemplaza desde el exterior, a diferencia del complemento que es interior. La retórica, en ese sentido, sigue siendo para Aristóteles exterior a la dialéctica -como sucedía también en Platón-, sin embargo, a falta de fuerza de aquélla, la retórica puede, casi imperceptiblemente, reemplazarla, usurparle su función. En ese sentido, y debido a su carácter exterior, la retórica es un peligroso suplemento.

Esta tesis de la retórica como suplemento del la dialéctica se sigue de la tesis derridiana de la escritura como suplemento del habla. La escritura es peligrosa y violenta porque siendo exterior al habla puede usurparle su lugar, reemplazarla, y en ese reemplazo adquirir más valor que aquella ${ }^{30}$. La escritura, como vimos en el Fedro de Platón, encanta, es

30 "Las ciencias y las artes' se han instalado en esta violencia, su "progreso" ha consagrado el olvido y "corrompido las costumbres". Saussure anagramatiza aún a Rousseau: "La lengua literaria agranda todavía la importancia inmerecida de la escritura ... la escritura se arroga de esta ventaja una importancia a que no tiene derecho" (p. 74). Cuando en relación con este tema los lingüistas se comprometen en un error teórico, cuando se dejan sorprender, son culpables, su falta es ante todo moral, han cedido a la imaginación, a la sensibilidad, a la pasión, han caído en la "trampa" (p. 73) de la escritura, se dejaron fascinar por el "prestigio de la escritura" (ibid.), de esta costumbre, de esta segunda naturaleza. "La lengua, pues, tiene una tradición oral independiente de la escritura, y fijada de muy distinta manera; pero el prestigio de la forma escrita nos estorba el verla." Por lo tanto no seríamos ciegos a lo visible, sino que estaríamos enceguecidos por lo visible, deslumbrados por la escritura. "Los primeros lingüistas se equivocaron 
como un hechizo, una droga que promete felicidad y lujo, pero que en el fondo mata a la memoria viva, la destruye y violenta. Sin embargo, esta usurpación suplementaria que lleva a cabo la escritura respecto del habla no es azarosa ni caprichosa; se da sólo cuando el habla carece del poder necesario para cumplir con plenitud su función de expresión del logos o del ser: "Cuando la naturaleza, como proximidad consigo, llega a ser prohibida o interrumpida, cuando el habla fracasa en la protección de la presencia, la escritura se torna necesaria. Debe urgentemente añadirse al verbo" ${ }^{1}$. Pero ese auxilio que presta la escritura al habla no es gratuito ni inocuo: “Ese recurso no es solamente 'bizarro', es peligroso. Es la adición de una técnica, es una suerte de astucia artificial y artificiosa para hacer presente al habla cuando, en verdad, está ausente. Es una violencia cometida contra el destino natural de la lengua" 32 . Al sacar de su pedestal epistémico a la dialéctica, Aristóteles convierte a la retórica en un suplemento necesario, sin el cual la dialéctica no podría cumplir con su rol a cabalidad. En Platón también podemos encontrar momentos en que la retórica y la escritura cumplen esta función suplementaria respecto del la dialéctica y el habla respectivamente, pero esos momentos se encuentran ocultos en el texto platónico, muy astutamente disimulados ${ }^{33}$. En Aristóteles, por el contrario, la capacidad suplementaria de la retórica queda claramente establecida desde el momento en que le concede todo un tratado, en el cual no sólo se describe su función, sino que además se afirma su valor y utilidad. La retórica es tan valiosa como necesaria en una organización política, pues sin ella no habría posibilidad de diálogo ni acuerdo con las masas indocumentadas. Pero, al igual que la escritura, puede ser muy peligrosa: "La escritura es peligrosa desde el momento en que la representación

en esto, como antes se habían equivocado los humanistas. Ni el mismo Bopp... Sus sucesores inmediatos cayeron en la misma trampa." Rousseau dirigía el mismo reproche a los Gramáticos: "Para los Gramáticos el arte del habla casi es el arte de la escritura". Como siempre la "trampa" es el artificio disimulado en la naturaleza. Esto explica que el Curso de lingüistica general trate ante todo este extraño sistema externo que es la escritura. Explicación previa necesaria. Para restituir lo natural a sí mismo es necesario ante todo desmontar la trampa". En Derrida, J. 1967b, pp. 55-56

31 Derrida, J. 1967b, p. 207

32 Ibidem.

33 Cf. Derrida, 2001. 
quiere hacerse pasar por la presencia y el signo por la cosa misma" ${ }^{\text {34 }}$. La retórica, en Aristóteles, no es siempre peligrosa, pero puede serlo cuando quiere hacerse pasar por la dialéctica, es decir, cuando, en lugar de dirigirse a las mayorías ignorantes, se dirige a los instruidos. Sin embargo, si esto pasa, es sólo por insuficiencia o incapacidad de la dialéctica: "Pero el suplemento suple. No se añade más que para reemplazar. Interviene o se insinúa en-lugar-de; si colma, es como se colma un vacío. Si representa y da una imagen, es por falta anterior de una presencia"35.

El problema de la adulación y el engaño, que Platón adjudica a la retórica, Aristóteles lo predica de otra práctica, derivada de la retórica, pero exterior a ella: la sofística. "La sofística no reside en la facultad sino en la intención. Y, por tanto, en nuestro tema, uno será retórico por ciencia y otro por intención" (1355b18-20). El de "retórico" era un nombre históricamente común -gracias a Platón- tanto al retórico con buena intención como al de mala intención -pues a ambos les llamó denostativamente "sofistas"-, por lo que, en vistas a esta diferencia crucial, Aristóteles propone llamarle sofista exclusivamente al segundo, mientras que el primero es un retórico propiamente tal, es decir, por arte. En el caso de Aristóteles, la sofística es también un suplemento de la retórica, pero éste sí es absolutamente peligroso y amenazante, pues es cuando el retórico se convierte en sofista que la gran amenaza del mal arriba a la polis. En la medida en que Platón identifica retórica y sofística, la retórica es desde siempre suplemento y peligro a la vez. Para Aristóteles, el suplemento no siempre es peligroso, es decir, suplementariedad y amenaza no van siempre unidas en un mismo gesto, como veíamos respecto de la dialéctica. Sin embargo, en la medida en que la retórica reemplaza en la dialéctica en los círculos intelectuales, o que la sofística reemplaza a la retórica, entonces aparece el escándalo: "Que el signo, la imagen o el representante se conviertan en fuerzas y hagan 'mover al universo', he aquí el escándalo"36.

34 Derrida, J. 1967b, p. 207

35 Ibid., p. 208

36 Ibid., p. 210 


\section{Bibliografía}

ARISTÓTELES (1990). Retórica. Madrid: Gredos.

-, (1984). De Interpretatione. En The complete Works of Aristotle, vol. 1. Princeton: Barnes.

(1984). Posterior Analytics. En The complete Works of Aristotle, vol. 1. Princeton: Barnes.

, (1984). Topics. En The complete Works of Aristotle, vol. 1.

Princeton: Barnes.

AUBENQUE, P. (1974). El problema del ser en Aristóteles. Madrid: Taurus

CALVO, T. (1996). Aristóteles y el aristotelismo. Madrid: Ediciones Akal.

COVARRUBIAS, A. (1998). La retórica deliberativa en la retórica de aristóteles. Una teoría de la argumentación entre las téchnai dialéctica y poética. Tesis Doctoral: Universidad Complutense de Madrid.

DE MAN, P. (1979). Allegories of Reading. Figural Language in Rousseau, Nietzsche, Rilke and Proust. New Haven, London: Yale University Press

DERRIDA, J. (1962). Introducción a "L'origine de la géométrie" de Husserl.

Paris: Presses Universitaires de France.

, (1967a). L'ecriture et la difference. Paris: Seuil.

(1967b). De la gramatologie. París: Minuit.

, (1972). Marges de la philosophie. Paris: Minuit

, (2001). La diseminación. Madrid: Fundamentos.

DIÓGENES LAERCIO, (2010). Vidas y opiniones de los filósofos ilustres, traducidas y comentadas por Luis-Andrés Bredlow. Zamora: Lucina.

FORTENBAUGH, W. (1970). Aristotle's Rethoric on Emotions. En Articles on Aristotle, IV. Psychology and Aesthetics. London: Duckworth.

FOUCAULT, M. (1992). El orden del discurso. Buenos Aires: Tusquets.

----------, (2004). Hermenéutica del sujeto. México: Fondo de cultura económica.

LOUIS, P. (1945). Les métaphores des Platon. Paris: Les Belles Lettres.

, (1986). La República. En Diálogos IV. Madrid: Gredos.

, (1986). Iii Fedro. En Diálogos III. Madrid: Gredos.

, (1974). Menon. En Obras Completas. Madrid: Aguilar.

, (1974). Gorgias. En Obras Completas. Madrid: Aguilar.

RACIONERO, Q. (1990). Notas a la Retórica de Aristóteles. Madrid: GREDOS.

VALLEJO CAMPOS, A. (1994). El Fedro y la Retórica de Aristóteles. Méthexis, VII. 